\title{
Medical Abortion of a First-Trimester Pregnancy with Large Multiple Uterine Leiomyomata
}

\author{
Somsook Santibenchakul $\mathbb{D}^{1,2}$ and Unnop Jaisamrarn $\mathbb{D}^{2}$ \\ ${ }^{1}$ Department of Obstetrics and Gynecology, King Chulalongkorn Memorial Hospital, Rama IV Road, Pathumwan, \\ Bangkok 10330, Thailand \\ ${ }^{2}$ Department of Obstetrics and Gynecology, Faculty of Medicine, Chulalongkorn University, Rama IV Road, Pathumwan, \\ Bangkok 10330, Thailand
}

Correspondence should be addressed to Somsook Santibenchakul; dr.somsook@gmail.com

Received 23 March 2021; Revised 13 May 2021; Accepted 5 June 2021; Published 21 June 2021

Academic Editor: Giovanni Monni

Copyright (c) 2021 Somsook Santibenchakul and Unnop Jaisamrarn. This is an open access article distributed under the Creative Commons Attribution License, which permits unrestricted use, distribution, and reproduction in any medium, provided the original work is properly cited.

\begin{abstract}
Introduction. Termination of pregnancy in a patient with huge uterine leiomyomata poses significant challenges to clinicians. In this study, we report the successful termination of pregnancy in a patient with large multiple uterine leiomyomata using a combined regimen of drugs for medical abortion. Case. A 42-year-old woman, 6 weeks pregnant, presented to the Family Planning Clinic with an unintended pregnancy. She had a large, irregular abdominal midline mass, equivalent in size to 30-32 weeks of pregnancy. Abdominal and transvaginal ultrasound examinations revealed a small intrauterine gestational sac with a yolk sac and multiple large uterine leiomyomata. Treatment with mifepristone $(200 \mathrm{mg})$ was initiated at the clinic. In addition, she was instructed to sublingually take $800 \mu \mathrm{g}$ of misoprostol after $24-48 \mathrm{~h}$. Two weeks later, at the follow-up visit, the patient complained of continued light bleeding. A pelvic examination showed that her cervix was dilated by $1 \mathrm{~cm}$. In addition, abdominal and transvaginal ultrasound revealed a thick, inhomogeneous endometrium. Owing to light bleeding and no anemia or infection, the patient received two additional doses of $800 \mu \mathrm{g}$ misoprostol vaginally. Her bleeding subsided for 61 days, and she resumed her normal menstrual cycle. Conclusion. A first-trimester pregnancy with large multiple uterine leiomyomata can be safely terminated using a combination regimen of drugs for medical abortion. However, an additional dose of misoprostol is required for the successful termination of pregnancy.
\end{abstract}

\section{Introduction}

Termination of pregnancy in a patient with a large uterine leiomyomata poses significant challenges to clinicians. A leiomyoma itself is not considered a contraindication for either medical or surgical abortion [1-3]. However, theoretically, it reduces myometrial contractility by weakening the uterine contractile force and impairing the expulsive mechanism $[4,5]$. Thus, it may decrease the success rate of medical abortions. Furthermore, a large uterine leiomyoma may distort the endometrial cavity, causing difficulties in surgical abortion [6]. Due to the rarity of this condition, only a few case reports and case series exist involving such cases [7-14] (Table 1). Therefore, this report shares our success in conservatively managing such difficult cases.

\section{Case Summary}

A 42-year-old patient who was 6 weeks pregnant, gravida 1, para 0, reported to the Family Planning Clinic due to an unintended pregnancy. The patient requested termination of pregnancy because of social and economic reasons. Her only symptom was that she had not had her menstrual period for one month. The patient's medical and surgical histories were unremarkable. Physical examination of the patient revealed a height of $154 \mathrm{~cm}$, weight of $75.3 \mathrm{~kg}$, and blood pressure of 110/67 mmHg. Abdominal examination revealed a large, irregular mass in the abdominal midline. During pelvic examination, the patient's vagina showed normal vaginal discharge and a closed cervix. The irregular midline mass, equivalent in size to a 30-32-week pregnancy, tended to move 
TABLE 1: List of a case series and seven reported cases of patients with large uterine leiomyomata who underwent abortion.

\begin{tabular}{|c|c|c|c|c|}
\hline $\begin{array}{l}\text { Authors/year of } \\
\text { publication }\end{array}$ & $\begin{array}{l}\text { Gestational age } \\
\text { (weeks)/remarks }\end{array}$ & $\begin{array}{l}\text { Description of leiomyoma/ } \\
\text { size of uterus }\end{array}$ & Description of intervention & $\begin{array}{l}\text { Induction to } \\
\text { abortion time }\end{array}$ \\
\hline $\begin{array}{l}\text { Saad-Naguib } \\
\text { et al. [7] } \\
2017\end{array}$ & 9 & $\begin{array}{c}18.1 \times 9.0 \times 15.7 \mathrm{~cm} \text { of subserosal } \\
\text { leiomyoma at posterior } \\
\text { wall of uterus } \\
20 \text {-week pregnancy }\end{array}$ & $\begin{array}{l}1 \mathrm{mEq} / \mathrm{mL} \text { of fetal intracardiac } \\
\text { potassium chloride injection } \\
\text { followed by } 2 \text { doses of } \\
20 \mathrm{mg} / \mathrm{m}^{2} \text { methotrexate }\end{array}$ & 2 weeks \\
\hline $\begin{array}{l}\text { Mark et al. [8] } \\
2016\end{array}$ & $\begin{array}{l}\text { 10-20 } \\
\text { Case series of } 12 \\
\text { patients }\end{array}$ & $\begin{array}{l}\text { Uterine sizes range from } \\
\text { 16- to } 32 \text {-week pregnancy }\end{array}$ & $\begin{array}{l}\text { For patients up to } 14 \text {-week } \\
\text { pregnancy, } 200 \mathrm{mg} \text { of oral } \\
\text { mifepristone followed by } 2 \\
\text { doses of } 800 \mu \mathrm{g} \text { misoprostol } \\
\text { vaginally } 24 \text { and } 48 \mathrm{~h} \\
\text { For patients beyond } 14 \text {-week } \\
\text { pregnancy, } 200 \mathrm{mg} \text { of oral } \\
\text { mifepristone followed by } \\
400 \mu \mathrm{g} \text { of misoprostol vaginally } \\
\text { every } 4-6 \mathrm{~h} \text { until delivery }\end{array}$ & $\begin{array}{l}\text { 6-17 h } \\
3 \text { patients } \\
\text { underwent uterine } \\
\text { evacuation due } \\
\text { to incomplete } \\
\text { abortion }\end{array}$ \\
\hline $\begin{array}{l}\text { Seto et al. [9] } \\
2013\end{array}$ & $\begin{array}{c}14 \\
\text { Prior classical } \\
\text { cesarean section }\end{array}$ & $\begin{array}{c}14 \times 10 \times 9 \mathrm{~cm} \text { subserous } \\
\text { leiomyoma arising from } \\
\text { posterior aspect of uterus } \\
16-18 \text {-week pregnancy }\end{array}$ & $\begin{array}{c}\text { Dilapan }{ }^{\circledR}-S^{1} \text { intracervically } \\
12 \mathrm{~h} \text { before } 3 \text { doses of } \\
\text { misoprostol vaginally every } \\
4 \mathrm{~h}(50,100, \text { and } 150 \mu \mathrm{g}, \\
\text { respectively) }\end{array}$ & $\begin{array}{l}9.5 \mathrm{~h} \text { after first dose } \\
\text { of misoprostol }\end{array}$ \\
\hline $\begin{array}{l}\text { Li et al. [10] } \\
2005\end{array}$ & 6 & $\begin{array}{l}\text { Nine measurable leiomyomata, } \\
\text { the largest of which measured } \\
10 \times 9 \times 9 \mathrm{~cm} \text { and was located } \\
\text { in the posterior lower uterine } \\
\text { segment } \\
24 \text {-week pregnancy }\end{array}$ & $\begin{array}{c}3 \text { tablets of } 200 \mathrm{mg} \\
\text { mifepristone and } 3 \mathrm{tablets} \\
\text { of } 200 \mu \mathrm{g} \text { misoprostol } 48 \mathrm{~h} \\
\text { later and then } 5 \text { tablets of } \\
200 \mu \mathrm{g} \text { misoprostol } \\
\text { vaginally }\end{array}$ & $\mathrm{NA}^{2}$ \\
\hline $\begin{array}{l}\text { Dalton and Lebovic [11] } \\
2003\end{array}$ & $\begin{array}{l}11 \\
3 \text { prior } \\
\text { unsuccessful } \\
\text { evacuation } \\
\text { attempts }\end{array}$ & $\begin{array}{l}\text { Multiglobular, heterogenous } \\
\text { masses with the largest's } \\
\text { diameter measuring } 8 \mathrm{~cm} \text { in the } \\
\text { posterior corpus, extending } \\
\text { cephalad, } \\
\text { and caudad } \\
\mathrm{NA}^{2}\end{array}$ & $\begin{array}{l}\text { Surgical abortion using a } \\
\text { flexible cannula }\end{array}$ & $\mathrm{NA}^{2}$ \\
\hline $\begin{array}{l}\text { Fenwick and } \\
\text { Divers [12] } \\
1995\end{array}$ & 6 & $\begin{array}{c}14 \times 10 \times 12 \mathrm{~cm} \text { intramural } \\
\text { leiomyoma } \\
24 \text {-week pregnancy }\end{array}$ & $\begin{array}{l}600 \mathrm{mg} \text { mifepristone orally, } \\
\text { followed by } 1 \mathrm{mg} \text { gemeprost } \\
\text { vaginally after } 36 \mathrm{~h}\end{array}$ & $\mathrm{NA}^{2}$ \\
\hline $\begin{array}{l}\text { Creinin [13] } \\
1996\end{array}$ & $\begin{array}{c}\text { 6-7 } \\
\text { History of } \\
\text { myomectomies }\end{array}$ & $\begin{array}{l}\text { Multiple leiomyomata } \\
\text { 25-week pregnancy }\end{array}$ & $\begin{array}{l}104 \mathrm{mg} \text { of methotrexate } \\
\text { intramuscularly, followed by } \\
\text { four tablets of } 200 \mu \mathrm{g} \\
\text { misoprostol vaginally } \\
6 \text { days later }\end{array}$ & $\begin{array}{l}3 \mathrm{~h} \text { after first dose of } \\
\text { misoprostol }\end{array}$ \\
\hline $\begin{array}{l}\text { Buckshee and } \\
\text { Dhond [14] } \\
1992\end{array}$ & 10 & $\begin{array}{l}\text { Large multiple leiomyomata } \\
\text { 32-34-week pregnancy }\end{array}$ & $\begin{array}{l}\text { Intra-amniotic and } \\
\text { intraplacental instillation of } \\
\text { methotrexate, } 25 \mathrm{mg} \\
\text { at each site }\end{array}$ & 8 days \\
\hline
\end{tabular}

${ }^{1}$ Dilapan $^{\circledR}$-S (synthetic osmotic cervical dilator; Gel-Med International, Kamenne Zehrovice, Czech Republic). ${ }^{2}$ No information available.

in conjunction with the cervix. Examination of the lower extremities revealed no signs of edema. In addition, abdominal and transvaginal ultrasound evaluation on her first visit confirmed that the patient had an intrauterine pregnancy along with multiple uterine leiomyomata. A detailed examination revealed that her uterus was $90 \times 33 \times 86 \mathrm{~mm}$ in size, including a small intrauterine gestational sac with a yolk sac. Multiple uterine leiomyomata of both intramural and subserosal types were found. These were located at the upper part of the posterior uterine wall, the upper part of the ante- rior uterine wall, the uterine fundus, the left lateral wall in the lower part of the uterus, and the right lateral wall in the lower part of the uterus. The sizes and volumes of these leiomyomata were (1) $35 \times 20 \times 32 \mathrm{~mm}$ (International Federation of Gynecology and Obstetrics (FIGO) classification: type O-3); (2) $12 \times 13 \times 10 \mathrm{~mm}$ (FIGO: type O-3); (3) $136 \times 108 \times 128$ $\mathrm{mm}, 984.4 \mathrm{~mL}$ (FIGO: type O-6); (4) $68 \times 71 \times 67 \mathrm{~mm}$, $169.4 \mathrm{~mL}$; and (5) $94 \times 65 \times 94 \mathrm{~mm}, 300.7 \mathrm{~mL}$, respectively. Thus, the diagnosis established based on ultrasound findings was an early intrauterine pregnancy with a large uterine 


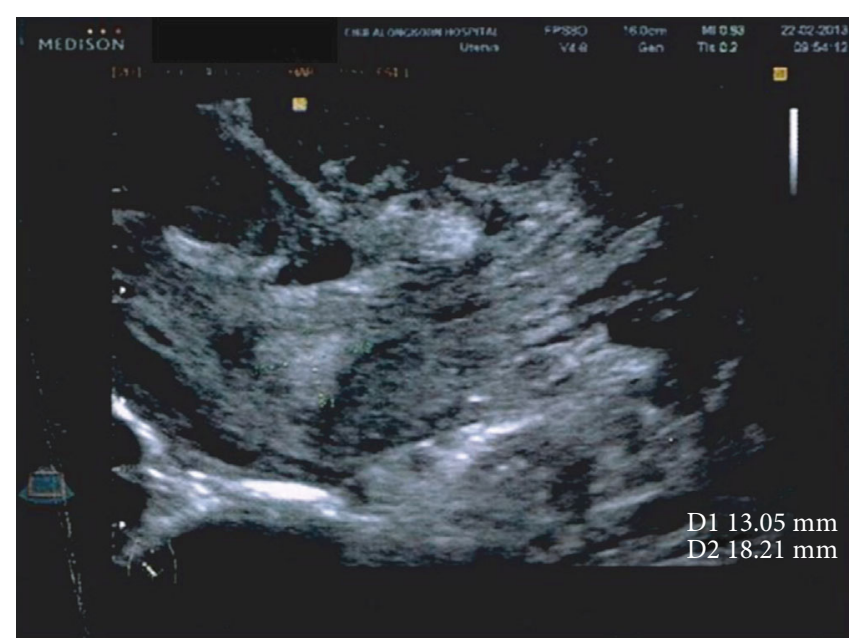

(a)

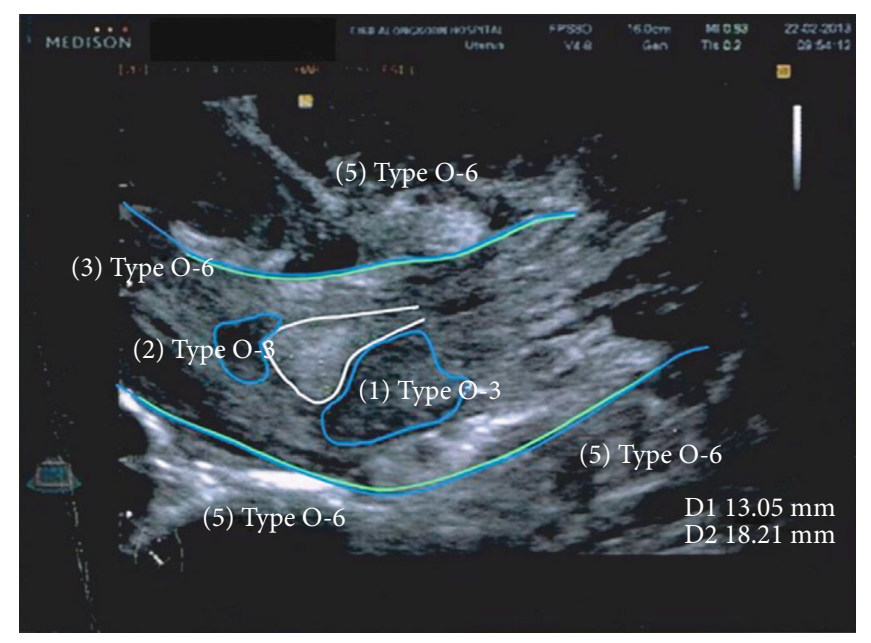

(b)

FIGURE 1: (a) Abdominal ultrasound (sagittal view of right lower abdomen) revealed an 18-millimeter-thick inhomogeneous endometrium with multiple intramural and subserosal leiomyomata (2 weeks after the combined regimen for medical abortion was administered). (b) Ultrasonic imaging revealing multiple leiomyomata (white line: endometrium; blue line: leiomyomata; green line: uterine wall) (Samsung Medison).

leiomyomata. After comprehensive reproductive healthcare counseling, the patient decided to undergo a medical abortion.

The patient was screened for the inclusion and exclusion criteria from a clinical trial of the introduction of medical abortion in Thailand [15], which assessed the acceptance of a combined regimen of drugs for medical abortion (Medabon $^{\circledR}$; Sun Pharmaceutical Industries Ltd, Mumbai, India) for Thai women in their first-trimester pregnancy. The patient was eligible for the clinical trial; therefore, $200 \mathrm{mg}$ of mifepristone was initiated at the clinic. In addition, she was instructed to take $800 \mu \mathrm{g}$ of misoprostol sublingually at home after 24-48 hours. An appointment was made to assess the completion of abortion two weeks after her first visit.

At the follow-up visit, the patient complained of continued light bleeding. Pelvic examination revealed that her cervix was dilated by $1 \mathrm{~cm}$. In addition, abdominal and transvaginal ultrasound revealed an 18-millimeter-thick inhomogeneous endometrium (Figure 1); thus, the abortion was classified as incomplete. Owing to light bleeding and no signs of anemia or infection, the patient was counseled according to her condition and various management options. She agreed to receive two additional doses of $800 \mu \mathrm{g}$ misoprostol vaginally, which were administered $72 \mathrm{~h}$ apart [16]. The patient's bleeding subsided for 61 days, after which she resumed her normal menstrual cycle.

\section{Discussion}

The present case report involves a successfully managed, difficult case of conservative termination of pregnancy in a patient with large multiple leiomyomata. In our opinion, medical abortion was the preferred method of treatment in this case. An intramural leiomyoma that is located in close contact with the endometrial cavity may impede the introduction of operative instruments into the uterine cavity, resulting in technically challenging and potentially dangerous operative abortions. Therefore, a medical abortion is the preferred treatment option in such cases $[6,7]$. A combined regimen of drugs for medical abortion was initiated in this case study, which comprised $200 \mathrm{mg}$ of mifepristone followed by $800 \mu \mathrm{g}$ of sublingual misoprostol with a $24-$ to 48-hour interval. This regimen is the most effective regimen for terminating first-trimester pregnancies [17]. Mifepristone is only available in some countries, and as of 2012, this medication was not available in Thailand. Fortunately, at that time, mifepristone was used in a clinical trial that investigated the acceptability of combined regimen medical abortion in Thai women [15].

Li et al. [10] used a combination of mifepristone and misoprostol to terminate pregnancy in the participants of their study. The authors prescribed $600 \mathrm{mg}$ of mifepristone followed by $600 \mu \mathrm{g}$ of misoprostol $48 \mathrm{~h}$ later. However, due to a lack of response to this regimen, an additional $1,000 \mu \mathrm{g}$ of misoprostol was vaginally administered. The medical abortion regimen used by $\mathrm{Li}$ et al. was different from our case because additional vaginal misoprostol in our case was administered because the abortion was deemed incomplete at the follow-up performed after two weeks. This case was unique in terms of the medical abortion regimen used. We followed the standard recommendations of the World Health Organization for the initial regimen for terminating the first trimester of pregnancy [18], and misoprostol was used to treat the incomplete abortion [16]. Mark et al. [8] reported a case series of 12 patients with large leiomyomata who had a successful medical abortion. For four patients who were under 14 weeks of gestation, the authors prescribed $200 \mathrm{mg}$ of mifepristone followed by two doses of $800 \mu \mathrm{g}$ of vaginal misoprostol 24 and 48 hours later. This medical abortion regimen is different from the regimen recommended by the World Health Organization for termination of pregnancy in patients under 12 weeks of gestation [18]. Among these 
four cases, one case had an incomplete abortion with heavy bleeding requiring blood transfusion and uterine evacuation. The uterine sizes of these four cases were equivalent to those of approximately 16-20 weeks of gestation.

The major limitation of this study that must be considered before generalizing to other patients is that this procedure should only be performed with great caution. Although additional doses of misoprostol may be prescribed for patients with an incomplete abortion [16], careful evaluation of the patient for the symptoms of anemia is required. In our case, we carefully evaluated the clinical manifestations of the condition in our case before prescribing additional athome misoprostol. The patient was instructed to return to the hospital immediately if her sanitary pads were soaked rapidly. Additionally, as this case had prolonged vaginal bleeding, concerning early signs and symptoms of any uterine infection is recommended. The patient was instructed to look for signs and symptoms of uterine infections, such as malodorous vaginal discharge, pelvic pain, and fever. She was also instructed to refrain from sexual intercourse and vaginal douching until the bleeding subsided. Lastly, as this patient had multiple uterine leiomyomata, they interfered with the quality of ultrasound imaging, and high-resolution ultrasound examination was required to evaluate both uterine leiomyomas and the completeness of abortion.

3.1. Patient Perspective. Our patient, who had not realized prior to visiting our clinic that she had huge leiomyomata, intended to end her pregnancy. After comprehensive counseling about the options to terminate pregnancy, she decided to choose a medical abortion to avoid a surgical procedure. The patient stated that the medicine was easy to use at home and gave her privacy. She complained of light bleeding for 61 days. This period was longer than expected. The patient also experienced abdominal discomfort, which required painkillers; however, her pain was not as severe as anticipated.

\section{Conclusion}

In this study, a first-trimester pregnancy with large multiple uterine leiomyomata could safely be terminated by using a combination regimen of medical abortion, comprising 200 $\mathrm{mg}$ of mifepristone followed by $800 \mu \mathrm{g}$ of sublingual misoprostol with a 24 - to 48-hour interval. However, an additional dose of misoprostol was still required, as the patient experienced continued bleeding due to an incomplete abortion. Clinicians must pay extra attention to any signs and symptoms of both anemia and uterine infection. A highresolution ultrasound was useful in evaluating the uterine leiomyomata and the success of the abortion.

\section{Conflicts of Interest}

The authors certify that there is no conflict of interest with any financial organization or other reasons regarding the material discussed in the manuscript.

\section{Acknowledgments}

We wish to thank Dr. Kittipong Saejeng, director at the Bureau of Reproductive Health, Department of Health, Ministry of Public Health, Thailand; Dr. Wanapa Naravage, Contraceptive Technologies and IEC manager; and Dr. Helena Von Hertzen, senior advisor on medical abortion at the Concept Foundation, for their support in "The Pilot Introduction of the Combination Package of Mifepristone and Misoprostol in Thai Health Service System." We sincerely thank Dr. Noppadol Chaiyasith for performing the ultrasound examination for this patient. This work was supported by the Family Planning \& Reproductive Health Unit, Department of Obstetrics and Gynecology, Faculty of Medicine, King Chulalongkorn Memorial Hospital, Bangkok, Thailand.

\section{References}

[1] Committee on Practice Bulletins-Gynecology and Society of Family Planning, "Medication abortion up to 70 days of gestation: ACOG practice bulletin, number 225," Obstetrics and Gynecology, vol. 136, no. 4, pp. e31-e47, 2020.

[2] D. Costescu and É. Guilbert, "No. 360-induced abortion: surgical abortion and second trimester medical methods," Journal of Obstetrics and Gynaecology Canada, vol. 40, no. 6, pp. 750-783, 2018.

[3] guideline NG140, N. I. C. E., Abortion care, Health economics, 2019.

[4] J. Szamatowicz, T. Laudanski, B. Bulkszas, and M. Åkerlund, "Fibromyomas and uterine contractions," Acta Obstetricia et Gynecologica Scandinavica, vol. 76, no. 10, pp. 973-976, 1997.

[5] P. Vergani, A. Ghidini, N. Strobelt et al., "Do uterine leiomyomas influence pregnancy outcome?," American Journal of Perinatology, vol. 11, no. 5, pp. 356-358, 1994.

[6] E. Gibson and C. A. Schreiber, "When uterine leiomyomas complicate uterine evacuation...," Contraception, vol. 82, no. 6, pp. 486-488, 2010.

[7] M. Saad-Naguib, K. Maguire, C. Curry, and U. Verma, "Medical first-trimester termination of pregnancy with massive fibroid uterus," Case Reports in Obstetrics and Gynecology, vol. 2017, Article ID 8203649, 2 pages, 2017.

[8] K. Mark, B. Bragg, K. Chawla, and K. Hladky, "Medical abortion in women with large uterine fibroids: a case series," Contraception, vol. 94, no. 5, pp. 572-574, 2016.

[9] M. T. Y. Seto, S.-F. Ngu, V. Y. T. Cheung, and T.-C. Pun, "Second trimester medical abortion in a woman with prior classical caesarean section and a uterine leiomyoma-a case report," The European Journal of Contraception \& Reproductive Health Care, vol. 18, no. 5, pp. 410-414, 2013.

[10] Y.-T. Li, T.-C. Kuo, Y.-C. Chu, S.-C. Hou, and F.-M. Chen, "Mifepristone and misoprostol induced abortion with a large myomatous uterus," Taiwanese Journal of Obstetrics and Gynecology, vol. 44, no. 2, pp. 175-176, 2005.

[11] V. K. Dalton and D. I. Lebovic, "Use of a flexible cannula to bypass an obstructing fibroid during a first-trimester surgical abortion. A case report," The Journal of Reproductive Medicine, vol. 48, no. 7, pp. 551-552, 2003.

[12] D. K. Fenwick and M. J. Divers, "Medical pregnancy termination in the presence of a massive uterine fibroid," The British Journal of Clinical Practice, vol. 49, no. 6, pp. 332-333, 1995. 
[13] M. D. Creinin, "Medically induced abortion in a woman with a large myomatous uterus," American Journal of Obstetrics and Gynecology, vol. 175, no. 5, pp. 1379-1380, 1996.

[14] K. Buckshee and A. J. Dhond, "A new nonsurgical technique for termination of intrauterine pregnancy associated with large multiple uterine leiomyomas," International Journal of Gynecology \& Obstetrics, vol. 37, no. 4, pp. 297-299, 1992.

[15] K. Saejeng, U. Jaisamrarn, and W. Naravage, "Women's experiences and acceptability of medical termination of pregnancy," Journal of Health Research, vol. 33, no. 2, pp. 127$137,2019$.

[16] J. Zhang, J. M. Gilles, K. Barnhart, M. D. Creinin, C. Westhoff, and M. M. Frederick, "A comparison of medical management with misoprostol and surgical management for early pregnancy failure," New England Journal of Medicine, vol. 353, no. 8, pp. 761-769, 2005.

[17] R. Kulier, K. Nathalie, A. Metin Gülmezoglu, G. Justus Hofmeyr, L. Cheng, and A. Campana, "Medical methods for first trimester abortion," Cochrane Database of Systematic Reviews, no. 11, article CD002855, 2011.

[18] World Health Organization, Medical Management of Abortion, World Health Organization, 2019. 